\title{
Balanço do programa de supervisão, apoio, acompanhamento e avaliação ao período probatório em Portugal - dos eixos de intervenção a uma visão prospetiva
}

Maria do Céu Roldão*

Pedro Reis**

Nilza Costa****

\section{Resumo}

Neste artigo faz-se uma análise global do impacto do Programa de Supervisão, Acompanhamento e Avaliação do Período Probatório de Professores (PSAAPPP) no que respeita aos seus principais eixos de intervenção - supervisão, formação e colaboração. Palavras-chave: Periodo probatório. Indução. Desenvolvimento profissional. Supervisão.

\section{Balance program oversight, support, monitoring and evaluation to probation in Portugal - the axes of intervention to a vision prospective vision}

\section{Abstract}

This paper presents a global analysis of the impact of the Probation Period required in Portugal to acceed to a permanent teaching position (PSAAPPP) - regarding its major intervention axis - supervision, teacher professional development and collaboration.

Keywords: Probation year. Induction. Professional development. Supervision.

* Pós-Doutorado em Teoria e Desenvolvimento Curricular; Professora e Investigadora da Universidade Católica Portuguesa. E-mail: mroldao@ucpcrp.pt

* Pós-Doutorado em Ciências Sociais-Ciências da Educação; Professor Auxiliar do Instituto da Universidade de Lisboa.E-mail: preis@ie.ul.pt

*** Pós-Doutorado em Didática e Formação e Tecnologia Educativa, Universidade de Aveiro; Coordenadora da unidade de investigação da Universidade de Aveiro.E-mail: nilza@dte.ua.pt 


\section{Balance del programa de supervisión, apoyo, acompañamiento y evaluación del período probatorio en Portugal - de los pilares de intervención a una visión prospectiva Resumen}

En este artículo se presenta un análisis global del impacto del Programa de Supervisión, Acompañamiento y Evaluación del Periodo Probatorio de Profesores (PSAAPPP) respecto a sus principales pilares de intervención - supervisión, formación y colaboración.

Palabras clave: Periodo probatorio de profesores. Inducción. Desarrollo profesional. Supervisión.

\section{Introdução}

Fechado o processo de intervenção e realizado o investimento investigativo que neste dossiê se procurou documentar, faz sentido fechar o arco do questionamento inicial destacando as principais linhas que a equipa de investigadores considera relevantes, e que correspondem ao caminho aberto pelos eixos de intervenção estabelecidos desde o início do processo - supervisão, formação, colaboração. Organizamos esta leitura final em três níveis de análise: (1) o nível macro - significado(s) no sistema; (2) o nível meso - impacte/potencialidades no desenvolvimento organizacional da escola; (3) o nível micro - desenvolvimento profissional dos docentes envolvidos e que constituía objetivo focal do programa.

\section{Nível macro - Significados no sistema}

A supervisão pode considerar-se praticamente inexistente no sistema educativo português nas últimas seis décadas, se excepcionarmos a supervisão de futuros professores no período de estágio, ainda integrada na sua formação inicial, ou situações pontuais no âmbito de projetos específicos. Um sistema que transporta algumas décadas de atraso no acompanhamento do movimento europeu de extensão da escolaridade e da exigência de formação pedagógica de todos os docentes - que só se começaram a construir como realidades com significado após a queda do Estado Novo em 1974 - não encarou durante muito tempo como centrais as lógicas de formação contextualizada e de atualização permanente dos seus professores no quadro dos seus lugares de trabalho. Sobrepôs-se por muito tempo, na cultura do sistema, a visão tendencialmente aceite, da formação entendida como preparação antes do exercício profissional, versus a sua incorporação na vida e gestão das escolas (CANÁRIO, 2009). Este défice no plano do sistema desincentivou a valorização da supervisão como um dispositivo eficaz e relevante de desenvolvimento organizacional e profissional e contribuiu para reforçar uma cultura individualista do exercício da docência, ancorada burocraticamente no reconhecimento tácito e inatacável da qualificação inicial como 
garante de competência do professor. A esta lógica, que permeou todo o sistema, corresponde a negatividade persistente de escolas e docentes face a dispositivos de supervisão, assimilados, na cultura de senso comum dominante, a controlo por parte da administração e a menoridade profissional dos eventuais supervisionados.

Programas de intervenção recentes, a nível do sistema, criados pela administração em colaboração com investigadores e universidades ou escolas de educação, intencionalmente dirigidos à formação intensiva e contextual de professores nas escolas, nas áreas de Português, Matemática e Educação em Ciência', ensaiaram alguma ruptura com esta rejeição instalada. Estes programas formativos de âmbito nacional, ao introduzirem trabalho supervisionado com colaboração entre investigadores e docentes de cada escola, que se mostrou útil ao desempenho dos professores envolvidos, desencadearam alguma aceitação e mostraram-se eficazes como potencial transformativo da visão instalada sobre a supervisão.

0 Periodo Probatório (PP), implantado pela primeira vez em 2009-10, e previsto no ECD, constituiu também uma tentativa de revalorização, ao nivel do sistema, da supervisão como dispositivo indutor de melhoria do desempenho, neste caso de professores em início de funções. Procurava-se desenvolver uma ação que colhesse ensinamentos de políticas anteriores mal recebidas, como a avaliação do desempenho docente (ADD). Parte da conflitualidade gerada pelo Estatuto da Carreira Docente $(E C D)^{2}$ e pelo Decreto Regulamentar n. ${ }^{0}$ /2008 (PORTUGAL, 2008), que regulamentou a ADD, centrou-se essencialmente na resistência ao estabelecimento da observação de aulas, supervisionadas por pares com funções avaliativas, que a sucessiva contestação da classe e as sucessivas negociações entre sindicatos e ministério da educação acabaram por reduzir a um mínimo sem significado no plano supervisivo. ${ }^{3}$

No plano político, o Programa de Supervisão, Acompanhamento e Avaliação do Período Probatório de Professores (PSAAPPP) foi instituído pela administração central como via para tentar reverter essa primeira experiência muito acidentada. Assim, neste outro momento avaliativo e formativo - o início da carreira - procurou-se salvaguardar a centralidade e importância de tais dispositivos supervisivos, para o que o Ministério da Educação contratualizou com uma Universidade a criação de um Programa de Apoio ao processo. Todavia, como a investigação descrita documenta (ROLDÃO, 2010; REIS, 2006; COSTA, 2010) tal desiderato não foi plenamente conseguido, por força das circunstâncias administrativas da

1 Programa Nacional para o Ensino do Português (PNEP), Plano da Matemática e Programa de Formação para o Ensino Experimental das Ciências. Conjunto de iniciativas ministeriais lançadas entre 2006 e 2009, com características diversas, mas assentes na formação em contexto e com apoio de supervisão.

2 Decreto-Lei n. ${ }^{\circ}$ 15/2007, de 19 de Janeiro - Sétima alteração do Estatuto da Carreira dos Educadores de Infância e dos Professores dos Ensinos Básico e Secundário, aprovado pelo Decreto-Lei n. ${ }^{\circ}$ 139- $^{139}$ A/90, de 28 de Abril, e altera o regime jurídico da formação contínua de professores, aprovado pelo Decreto-Lei n. ${ }^{\circ}$ 249/92, de 9 de Novembro.

3 Na última versão da legislação a que nos reportamos, 2 aulas observadas, a pedido do avaliado, e apenas se pretendesse que fosse considerada a sua avaliação nos níveis Muito Bom ou Excelente. 
operacionalização desta primeira implementação do ano probatório, onde desde o início, predominaram as lógicas administrativas sobre as lógicas do desenvolvimento profissional, organizando-se, por exemplo, o processo em função da distribuição dos formandos por grupos de recrutamento, e recorrendo o sistema a mentores necessariamente da mesma escola, 0 que, na prática, veio a gerar uma dispersão geográfica excessiva, com um par formando/ mentor em cada uma das quase cem escolas. Esta dispersão e isolamento de cada contexto de APP constituiram parte das dificuldades da ação a desenvolver pelo PSAAAPPP.

A equipa responsável pelo PSAAAPPP procurou converter estas dificuldades em oportunidades, reforçando justamente o apoio-formação aos atores mandatados para exercer a supervisão (os Professores Mentores - PM), na perspetiva teórica que se subscreve da centralidade do processo supervisivo como fator de desenvolvimento profissional (ALARCÃO; ROLDÃO, 2008; COSTA, 2003; ROLDÃO, 2009, 2010; MARCELO, 2009; REIS, 2006, 2011).

Do balanço deste ano de investimento resultam alguns ganhos e bastantes perdas no plano do sistema. Como destaques positivos, ao nível macro, os testemunhos recolhidos tendem a acentuar alguma ruptura na visão culturalmente dominante, assinalando abertamente a valia da supervisão e o reconhecimento dos ganhos formativos após a inicial resistência por parte dos sujeitos envolvidos. Todavia, ao nível da continuidade política da medida, e da correção dos desajustes organizativos sugerida no relatório da equipa (COSTA, 2010) sucedeu-se, até ao momento, o abandono efetivo da implementação da medida. Por outro lado - como algumas vozes dos professores envolvidos testemunham - nada foi feito no plano da administração para rentabilizar e melhorar o esforço desta primeira tentativa: qualquer repetição do processo permanece remetida para um futuro agora distante ${ }^{4}$.

No eixo da supervisão, o PSAAAPPP correspondeu a um reconhecimento por parte da Administração da importância de valorizar os dispositivos de supervisão nos processos avaliativos. Introduziu alguma ruptura na visão dominante acerca da finalidade da supervisão no sistema, mas com escasso impacte no sistema como um todo.

No que se refere ao eixo da formação, os dados analisados nos artigos que constituem este dossiê temático permitem visualizar evidências do reconhecimento da valia desta dimensão na efetiva implementação do apoio dos PM aos PPP. Infere-se ainda da análise dos testemunhos dos sujeitos que o reconhecimento da utilidade da formação dos PM foi lido como resultando da lógica formativa adotada, em que

4 A progressão dos docentes na carreira, mediante subida de escalão, está congelada desde Julho de 2011, na decorrência da crise financeira que o país atravessa. Assim, como, na legislação mais recente sobre a carreira docente e a avaliação de desempenho (DL n ${ }^{\circ}$ 41/2012, de 21 Fevereiro, e DR ${ }^{\circ}$ 26/2012) toda a estrutura de procedimentos de ADD está remetida para o ano que antecede a mudança de escalão, na prática a ADD está efetivamente suspensa até que a situação se altere, o mesmo se passando com o Período Probatório. 
se trabalhou, segundo um modelo teórico de mútua alimentação teoria-prática, e de equilibrio entre 0 apoio às dificuldades da implementação no terreno (LEITE, 2011). Observa-se alguma evolução nos testemunhos dos PM, de uma expectativa inicial de apoio à resolução prática de situações problemáticas para uma adesão a lógicas mais analíticas e reflexivas como alimento da formação. Contudo, este efeito é mitigado, nas Reflexões dos PM (ROLDÃO, 2010), pela retoma, por parte dos sujeitos, da afirmação da necessidade, para situações futuras, duma formação preferencialmente prévia à ação, susceptível de securizar os atores, neste caso os PM. Mantém-se assim a tensão dialética, expectável, entre o reconhecimento das vantagens de uma formação assente no desenvolvimento da experiência e na sua teorização versus uma leitura mais técnico-aplicacionista dos processos formativos.

A dimensão formação, eixo central da intervenção do PSAPP, sofreu ainda as limitações decorrentes de não ter atingido diretamente o segundo grupo de intervenientes, os PPP. Esta limitação nuclear teve, ainda assim, um tratamento positivo no desenvolvimento do processo, na medida em que, para superar essa dificuldade, se mobilizou, com sucesso, a valia do trabalho colaborativo e da mediação dos PM.

\section{Nivel meso - Impacte/potencialidades no desenvolvimento organizacional das escolas}

Esta dimensão foi a que se reconhece como menos potenciada pelo PSAAAPP, por força das circunstâncias organizativas sem dúvida, mas também como resultado expectável face à opção estratégica que foi tomada: centrar o investimento nos atores docentes diretamente envolvidos - PM e PPP - remetendo para efeitos laterais parcialmente induzidos a dinamização do impacte nas vertentes organizacionais da escola.

A implicação organizacional que se tentou ainda assim dinamizar a partir do processo de formação, foi tentada através do aproveitamento (sugerido pelos PM mas raramente acolhido pelas lideranças das escolas) dos debates e práticas supervisivas em curso no processo de apoio aos PM aos departamentosdisciplinares em que os PPP e os PM se integravam. Este esforço, traduzido, em casos pontuais, na realização de alguns seminários nas escolas, visava romper a lógica predominantemente burocrática e administrativa dominante no trabalho dos departamentos em favor de uma maior focagem na ação pedagógico-didática e sua melhoria. A pequena escala do processo (um PM e um PPP por escola, na larga maioria das situações) foi claramente inibidora da eficácia deste esforço transformativo estrutural nas dinâmicas das escolas.

A equipa do PSAAAPPP desenvolveu outra via de acesso a esta dinamização organizacional, através da convocação/convite aos diretores de escola/ agrupamento para que se apropriassem do processo. Para o efeito realizou-se, para além do convite aos diretores para os seminários nacionais de abertura e 
fecho do programa, um encontro a meio do processo, dirigido exclusivamente a todos os diretores das escolas, que teve uma afluência relativamente baixa (menos de 40\%). Recorde-se que não existia qualquer poder hierárquico por parte da equipa para esta convocação, por isso o encontro em causa foi apenas objeto de convite aos diretores.

Os diretores que participaram neste encontro e nos dois seminários nacionais manifestaram, em questionário que lhes foi submetido (REIS, 2011), preocupação central com as dimensões organizativas e administrativas do processo e com as regras da avaliação dos PPP em articulação com a ADD. Este posicionamento indicia o predomínio de uma certa lógica gerencial por parte das lideranças, por um lado e, por outro, reflete também a prioridade que, no momento conturbado que se vivia, atribuiam à gestão das situações de conflitualidade nas escolas relativamente ao processo de ADD. Foi muito claro o escasso interesse em se envolverem mais no processo, cujo acompanhamento Ihes surgia como já garantido pela equipa da Universidade de Aveiro, não se posicionando como corresponsáveis.

Conclui-se assim que a dinamização organizacional das escolas ou a contaminação de lógicas de desenvolvimento profissional em ação no APP para as estruturas das escolas/agrupamentos ${ }^{5}$ globalmente não ocorreu.

Os pontos fortes referidos pelos sujeitos, no plano das escolas, situam-se sobretudo na ruptura que o processo "forçou" entre a lógica estritamente disciplinar e as lógicas pedagógico-didáticas mais transversais, que resultaram da necessidade de ultrapassar as pertenças disciplinares muitas vezes diversas, ainda que afins, dos PM e dos seus PPP. Outra linha de impacte reporta-se à instauração e adesão a modos de trabalho colaborativo, contrários à tradição de trabalho individual dominante no que se refere à docência de cada professor. Todavia este efeito limitou-se aos intervenientes. Retira-se destes factos, no plano investigativo, o reconhecimento de que a intervenção transformadora efetiva terá de atender, e agir de modo intencional, face à articulação do nivel do desempenho individual do profissional com o nivel da organização que o enquadra e onde se molda a sua socialização profissional (CANÁRIO, 2005).

\section{Nivel micro - 0 desenvolvimento profissional dos docentes envolvidos}

0 nivel micro dos eixos de intervenção desenhados pelo PSAAAPP foi na verdade o seu foco principal de ação. Os impactes mais visiveis do Programa,

5 Conjuntos de escolas de uma zona que se associam em torno de uma administração e de projetos educativos e curriculares comuns. 
que se analisaram ao longo dos artigos deste dossiê, situam-se na transformação observada e evidenciada das atitudes e crenças dos intervenientes face ao processo formativo que, na sua larga maioria, remetem para um reconhecimento muito positivo. Como limitações desta vertente da formação, que colocámos no centro do Programa, importa relembrar que toda a recolha foi mediada pela voz dos sujeitos, não tendo sido possível o acesso direto às práticas ou o acompanhamento direto dos contextos, nem a formação ou outras intervenções diretas junto dos PPP. Também não existem evidências que permitam inferir a permanência dos efeitos descritos na continuidade do trabalho posterior dos sujeitos. Uma pesquisa interessante poderá vir a incidir sobre os percursos subsequentes dos atores que vivenciaram esta experiência.

Entre os impactes positivos mais evidenciados no discurso dos atores situam-se as aprendizagens profissionais, relativas ao ato de ensinar e à sua adequação aos aprendentes, o reconhecimento de níveis de relativo défice de saber (inicialmente não admitidos) e da necessidade permanente de melhorar, o acolhimento da componente teórica do saber profissional e a aceitação muito clara da valia do trabalho colaborativo e da supervisão entre pares. Foi também patente um crescente sentido de autonomia e de autoria, visibilizado nas prestações dos pares PPP e PM no Seminário final do Programa, quer através dos pôsteres e do trabalho de feedback que os antecedeu (analisados em texto de Campos e Gonçalves, neste dossiê) quer na participação pública nas Mesas Redondas desse evento, lideradas pelos próprios formandos.

A transformação da perspectiva dos profissionais envolvidos no processo face à valia da supervisão (PPP e PM) visada no PSAAAPP, e a sua tradução num apoio que fosse reconhecido pelos sujeitos como patamar de construção de saber e desenvolvimento profissional, apresenta-se aos investigadores com um nivel de consecução bastante positivo. Já a sua consolidação no plano organizacional, ou a contaminação das lógicas formativas, supervisivas e colaborativas gizadas aos pares profissionais e às estruturas ficou claramente aquém do desejável. Esta verificação, que a investigação realizada permitiu, ilustra a necessidade politica de abordagens articuladas (macro, meso e micro) que convoquem e intencionalizem a intervenção no sentido holístico que a melhoria da qualidade educativa requer. Evidencia também a centralidade de processos de formação contextualizada e supervisão coconstrutiva na transformação desejada de culturas e modos de socalização profissional que se têm caracterizado pela visão individualista do ensino e por uma ausência persistente de dispositivos analiticos e avaliativos. 


\section{Referências}

ALARCÃO, I.; ROLDÃO, M. C. Supervisão: um contexto de desenvolvimento profissional dos professores. 2. ed. Mangualde: PEDAGO, 2008.

CANÁRIO, R. A escola: o lugar onde os professores aprendem. In: CONGRESSO DE SUPERVISÃO, 1., 2009, Aveiro. Atas... Aveiro: Universidade de Aveiro, 2009. p. 11-23.

CANÁRIO, R. O que é a escola?: um olhar sociológico. Porto: Porto, 2005.

COSTA, N.; MARTINS, I.; CANDEIAS, I. Avaliação e regulação do desempenho profissional. Aveiro: Universidade de Aveiro, 2010. (Coleção Situações de Formação n. 4).

COSTA, J.; NETO-MENDES, A. S.; SOUSA, L. (Org.). Avaliação das organizações educativas. Aveiro: Universidade de Aveiro, 2003.

LEITE, T. Planeamento e conceção da ação de ensinar. Aveiro: Universidade de Aveiro. Aveiro: Universidade de Aveiro, 2010. (Coleção Situações de Formação n. 2).

MARCELO, C. Desenvolvimento profissional docente: passado e futuro. Sísifo: Revista de ciências da educação, Lisboa, n. 8, jan./abr. 2009.

PORTUGAL. Ministério da Educação. Decreto Regulamentar no 4, de 5 de Fevereiro de 2008. 0 presente decreto regulamentar define a composição e 0 modo de funcionamento do conselho científico para a avaliação de professores. Diário da República, n. 25, de 5 de fevereiro de 2008. Série 1, p. 913-915.

REIS, P. Uma iniciativa de desenvolvimento profissional para a discussão de controvérsias sociocientíficas em sala de aula. Interacções, Portugal, v. 2, n. 4, p. 64-107, 2006. Disponivel em: <http://revistas.rcaap.pt/interaccoes/article/ view/321/277>. Acesso em: 10 abr. 2012.

REIS, P. A gestão do trabalho em grupo. Aveiro: Universidade de Aveiro, 2011. (Colecção Indução e Desenvolvimento Profissional Docente).

ROLDÃO, M. C. Ensinar e aprender: o saber e o agir distintivos do profissional docente. In: ENS, R. T.; BEHRENS, M. A. (Org.). Formação do professor: profissionalidade, pesquisa e cultura escolar. Curitiba: Ed. Champagnat, 2010. p. 25-42.

. Formação de professores na investigação portuguesa: um olhar sobre a função do professor e o conhecimento profissional. Formação Docente: Revista brasileira de pesquisa sobre formação de professores, Belo Horizonte, v. 1, n. 1, ago./dez. 2009.

Recebido em: 12/04/2012

Aceito para publicação em: 18/07/2012 